\title{
Chronopsychological mental development dysontogenesis prognosing in pre-school children
}

\author{
Iryna Savenkova ${ }^{1}$, Mykola Didukh', Inna Chuhueva', Iryna Litvinenko ${ }^{1}$
}

\begin{abstract}
Objective: Mental development dysonotogenesis is a rather complicated and at the same time insufficiently researched issue concerning children with special needs. This is one of the most urgent problems of modern special and age psychology, since the definition of the type of dysontogenesis for different mental disorders is necessary for a special psychologist, teacher and speech therapist, first of all, in order to understand the mechanisms of formation of cognitive, emotional and speech disorders and their place in the defect structure. Objective methods of psycho-pedagogical dilant diagnostics to present date do not exist. Therefore, the purpose of the study was to develop an algorithm for chronopsychological prognosing of the mental development dysonotogenesis.

Method: An experimental method of chronometric test using an electronic chronoscope; methods of mathematical statistics (descriptive statistics, percentile statistics, methods of averages, comparison of mean values using the Student's t-test.).

Results: Comparing the quadratic deviations of $\sigma$ (quality index of an individual clock) in subjects of a representative sample with the level of their psychometric intelligence (IQ), a simple dependence was obtained: the smaller $\sigma$, the higher the IQ of personality. The quality of an individual's watch, like the clock itself, is congenital, so the quality score $(\sigma)$ should be considered as one of the indicators of the basic intellectual potential ("factor $\mathrm{g}$ ") of the individual. The mathematical analysis of the study results showed that oligophrenia and children with mental development delay have a different deviation from the analogue of the "qualitative" clock. In children with mental development delay, there is a deviation from the accuracy of given intervals of time reproduction only from 0.03 to 0.05 . In mentally retarded children it is from 0.05 to 0.1 and not less. It enables to objectively predict the form of the manifestation of the preschool children mental development dysontogenesis, which is an important diagnostic criterion for assessing the mental status of a child.

Conclusion: The choice of psychological and temporal indicators of the mental development dysontogenesis course allowed to develop an algorithm of chronopsychological prediction of the mental disorder manifestation form, the essence of which is that the subjective time unit of the individual acts as a central factor, which allows predicting the dysonotogenesis manifestation form, that is, to determine whether the diagnosis is mental retardation or delayed mental development. In the case of mental retardation, the unit itself is stable, i.e. does not change during the life of the reproduction of different periods of time. With mental retardation, it changes in a jumping manner, depending on the mental defect depth. In other words, due to the jump in the oligophrenic psyche there is no proper structure of the direct experience of time. Therefore it becomes possible to assume that in such groups of children there is a difficulty in the assimilation of time concepts, the difficulty in shaping the imagination of the metric properties of time, and the violation of the orientation in the past and the future in oligophrenic children is largely determined by the deviation from the analogue of "qualitative" watches. The consistent implementation of the stages of our chronopsychological prognosing algorithm, which could be relatively easy to be adapted for use in special pedagogy, would provide the opportunity to achieve the greatest effect in conducting a psychological and pedagogical examination of children with mental development dysontogenesis.
\end{abstract}

Keywords: chronopsychological prognosing, dysontogenesis of mental development, subjective time unit of individual, chronopsychological mental

\section{INTRODUCTION}

Objective prediction of mental development dysonotogenesis type (mental retardation or delayed mental development) is one of the most urgent problems of modern special and age psychology (1), since the definition of the type of dysontogenesis for various mental disorders is necessary for a psychologist, a teacher and speech therapist, first of all, in order to understand the mechanisms of formation of cognitive, emotional and speech disorders and their place in the structure of the defect. This knowledge is needed, in particular, to choose the program of inclusive education, which should be followed by the child, and at the same time the specialists who will provide the child with help (special

1 Sukhomlynskyi Mykolaiv National University, Nikolaev, Ukraine.

Received: 28 Aug 2018, Accepted: 11 Feb 2019
Correspondence: Iryna Savenkova

Department of Psychology, Sukhomlynskyi Mykolaiv National University, Nikolaev, Ukraine.

E-mail: savenkova-1966@ukr.net

(c) 2019 by the authors; licensee Modestum Ltd., UK. This article is an open access article distributed under the terms and conditions of the Creative Commons Attribution License (http://creativecommons.org/licenses/by/4.0/). 
psychologist, speech therapist, correctional teacher, etc.). The qualification of the mental dysonotogenesis type is also important in conducting differential diagnosis (2).

In general, the concept of dysontogenesis, as a deviation from normal individual development at any stage of life, from the moment of fertilization and ending with death, is widely used to explain the causes of the different congenital and acquired pathologies of mental development formation (3). A child with a slight degree of mental retardation can develop only within the limits of the biological capabilities of the body of this particular child. Consequently, we can conclude that the prognosis for the development of such a child will depend on the degree of mental retardation and the system of correctional training and upbringing of the person. Such scholars as $(4,5)$ note that in children with delayed mental development, there is a significant difference between the results of an independent solution of the issue by a child and its solution with the help of an adult. They believe that this indicates a large potential for correction of this developmental disorder. Y. Slepovich (4), notes that in providing a qualified psychological and pedagogical assistance, especially in preschool age, a child with delayed mental development, may reach a normal level of development.

Proceeding from the above, the relevance and insufficient development of the issue of mental development dysonotogenesis prognosing is beyond doubt (6).

The cause of the occurrence of dysonotogenesis cannot be understood without knowledge of the psychological characteristics of the child's personality, and without it, it is difficult to predict the course of such a disorder (7).

The psychological differentiation of individual psychological properties of a person shows that the signs of mental disorders are fully consistent with them and, accordingly, can be sufficiently predicted and determined taking into account typological groups, as well as dependent on the individual (subjective) biological time $(8,9,10,11,12)$.

As shown by the analysis of scientific literature on the problem of the research, the study of the interrelations and interdependence of the mental development dysontogenesis (on the example of mentally retarded children and children with delayed mental development) from the time parameters, as well as their correlation, remained beyond the attention of scientists $(5,13,14,15)$.

Concurrently, the questions of manifestation of the mental development dysontogenesis of each separate nosological form in the chronotype typological group remain open in the described field. This information will create opportunities for a significant increase in the potential of psychological and pedagogical examination of children with mental development dysontogenesis.

Therefore, the purpose of the study was to develop an algorithm for chronopsychological prediction of the dysonotogenesis of mental development.

Hypothesis. Based on these studies, we had posed the hypothesis that the mentally retarded subjects throughout the chronometric testing process show apparent deviations in the accuracy of conducting the test. In order to test the hypothesis, the study was conducted on children with special needs and children with delayed mental development.

Therefore, the purpose of the study was to develop an algorithm for chronopsychological prognosing of the mental development dysonotogenesis.

And the main tasks (stages) are as follows:

1. Separation of psychological and temporal indicators of prognosing mental development dysontogenesis by the experimental method of chronometric probe using an electronic chronoscope for children with mental retardation and delayed mental development, with a goal of differentiating these states.

2. Calculation of the relative reproduction error of the proposed time intervals.

3. Comparison of quadratic deviation of $\sigma$ (individual clock quality index) in the subjects of the representative sample with the level of their psychometric intelligence (IQ).

\section{MATERIALS AND METHODS}

Participants. 52 children aged 6 to 7 years with dysonotogenesis of mental development, including 8 girls and 8 boys aged 6 to 7 with mental retardation and 36 children with delayed mental development (17 girls and 19 boys) aged 6 to 7 years.

The choice of such contingent is due to the need for psychological and pedagogical examination of children of this age category in order to determine the program of inclusive education, which should be taught to children with mental development dysontogenesis. The algorithm developed by us was practically tested and implemented into practice on the basis of the comprehensive psychological and pedagogical examination of children with intellectual disabilities and children with delayed mental development. 
Table 1: Relative error of reproducing the duration by "extroverted subject"

\begin{tabular}{|c|c|c|c|c|c|c|}
\hline \multirow{2}{*}{$t_{o}(\sec )$} & \multicolumn{3}{|c|}{1 sample (10 ind.) } & \multicolumn{3}{|c|}{2 sample (10 ind.) } \\
\hline & $t_{s}(\mathrm{sec})$ & Chr & $\varepsilon(\%)$ & $t_{s}(\mathrm{sec})$ & Chr & $\varepsilon(\%)$ \\
\hline 2 & 1.7 & 0.85 & 15 & 1.68 & 0.84 & 16 \\
\hline 3 & 2.52 & 0.84 & 16 & 2.49 & 0.83 & 17 \\
\hline 4 & 3.32 & 0.83 & 17 & 3.28 & 0.82 & 18 \\
\hline 5 & 4.1 & 0.82 & 18 & 4.15 & 0.83 & 17 \\
\hline \multicolumn{2}{|c|}{ Average } & 0.84 & 16.5 & - & 0.83 & 17 \\
\hline
\end{tabular}

NOTE: $t_{0}$ - the duration given by the experimenter

$t_{s}$ is the duration that the surveyed reproduces

$\varepsilon(\%)$ - reproduction of duration determined for the experimental group as 1 sample (children with mental development disontogeny). The second group is control group as 2 sample (healthy children of this age group). The error was calculated using the formula

Organization of research. Our task to predict the course of mental development dysontogenesis has been solved experimentally in the contingent of mentally retarded children and children with delayed mental development of age from 6 to 7 years old who visit the Kiev preschool educational institution № 569 for children with intellectual disabilities and the Kiev preschool educational institution № 801 for mentally retarded children. In other words, the study was conducted with the aim of differentiating the mental states of these groups of children and identifying the criteria for predicting the dysonotogenesis course.

On the basis of the chronometry results, a table was constructed to determine the chronotype of the individual. For each patient who was examined using a chronometric test method (16) the "chronotype" was determined, using the classic method of reproducing intervals of duration $t_{0}=2,3,4,5 \mathrm{~s}$, set by the experimenter and reproduced by the patient on an electronic chronoscope with precision to $0.001 \mathrm{~s}$. At the same time, each examinee was asked to recreate the duration he experienced limited to two signals - "start" and "finish" in the form of sound that occurs when turning on and stopping the chronoscope. The subjects reproduced the intervals that were entered to this chronoscope.

The individual value of the "chronotype" was calculated by the formula according to each proposed interval:

$$
X_{T}=\frac{\sum t_{s}}{\sum t_{0}}
$$

where $t_{0}$ is the duration given by the experimenter, and $t_{s}$ is the duration reproduced by the examinee.

The reproduction of each time interval was repeated five times, and then the average value of the chronotype of each subject was counted. This relation was first proposed by G. Ehrenwald (17) to characterize the individual results of the reproduction method.

\section{RESULTS}

Statistical analysis. In our research, the relative error of duration reproduction was determined for the experimental group - 1 sample (children with mental development dysonotogenesis) and control 2 sample (healthy children of this age category), and were calculated by the formula:

$$
|\varepsilon|=\frac{\Delta t_{s}}{t_{0}} 100 \%
$$

where $\Delta t=t_{0}-t_{s}, t_{0}-$ duration, set up by the researcher, and $t_{s}$ - duration, recreated by the patient (16). The results were compared to the chronotype value and are presented in Tables 1-3. As can be seen from Tables 1-3, in two independent samples, the "extraverted", "ambiverted" and "introverted" subjects practically received the equality of relative errors. Therefore, it can be assumed that by the method of time period reproduction is investigated the stable mechanism of reproducing audible time intervals, which measures the flow of time experienced by the subject. In other words, the subject has a chronotype, by means of which the measured duration is directly experienced (18). 
Table 2: Relative error of reproducing the duration by "ambiverted subject"

\begin{tabular}{|c|c|c|c|c|c|c|}
\hline \multirow{2}{*}{$t_{o}(\sec )$} & \multicolumn{3}{|c|}{1 sample (10 ind.) } & \multicolumn{3}{|c|}{2 sample (10 ind.) } \\
\hline & $t_{s}(\mathrm{sec})$ & Chr & $\varepsilon(\%)$ & $t_{s}(\mathrm{sec})$ & Chr & $\varepsilon(\%)$ \\
\hline 2 & 1.8 & 0.9 & 10 & 1.78 & 0.89 & 11 \\
\hline 3 & 2.67 & 0.89 & 11 & 2.64 & 0.88 & 12 \\
\hline 4 & 3.52 & 0.88 & 12 & 3.48 & 0.87 & 13 \\
\hline 5 & 4.35 & 0.87 & 13 & 4.4 & 0.88 & 12 \\
\hline \multicolumn{2}{|c|}{ Average } & 0.89 & 11.5 & - & 0.88 & 12 \\
\hline
\end{tabular}

NOTE: $t_{0}$ - the duration given by the experimenter

$\mathrm{t}_{\mathrm{s}}$ is the duration that the surveyed reproduces

$\varepsilon(\%)$ - reproduction duration determined for the experimental group as 1 sample (children with mental development disontogeny). The second group is control group as 2 sample (healthy children of this age group). The error was calculated using the formula

Table 3: Relative error of reproducing the duration by "introverted subject"

\begin{tabular}{|c|c|c|c|c|c|c|}
\hline \multirow{2}{*}{$t_{0}(\sec )$} & \multicolumn{3}{|c|}{1 sample (10 ind.) } & \multicolumn{3}{|c|}{2 sample (10 ind.) } \\
\hline & $t_{s}(\mathbf{s e c})$ & Chr & $\varepsilon(\%)$ & $t_{s}(\mathbf{s e c})$ & Chr & $\varepsilon(\%)$ \\
\hline 2 & 2.6 & 1.3 & 30 & 2.54 & 1.27 & 27 \\
\hline 3 & 3.66 & 1.22 & 22 & 3.84 & 1.28 & 28 \\
\hline 4 & 5 & 1.25 & 25 & 5.2 & 1.3 & 30 \\
\hline 5 & 6.35 & 1.27 & 27 & 6.25 & 1.25 & 25 \\
\hline \multicolumn{2}{|c|}{ Average } & 1.26 & 26 & - & 1.275 & 27,5 \\
\hline
\end{tabular}

NOTE: $t_{0}$ - the duration given by the experimenter

$t_{s}$ is the duration that the surveyed reproduces

$\varepsilon(\%)$ - reproduction duration determined for the experimental group as 1 sample (children with mental development disontogeny). The second group is control group as

2 sample (healthy children of this age group). The error was calculated using the formula

Thus, the results of the reproduction duration relative error in the experimental group are equivalent to the results of the reproduction duration relative error in the control group and are subject to unambiguous interpretation. Therefore, the duration reproduction method can be considered adequate for prognosing the course of the mental development dysontogenesis from the standpoint of the experience of time laws.

In this regard, the specificity of the reproduction method can reveal the peculiarities of the "time mechanism" of the individual, which measures the length of time experienced by the subject through his chronotype.

Our further research was aimed at detecting a deviation from the analogue of "good" hours in mentally retarded children and children with delayed mental development. According to the World Health Organization, a deviation from the psychological norm of intelligence (mental retardation) is observed in 1-3\% of the total population of the planet (10). The boundaries between the norm and mental retardation are indicated, and the differentiation of the latter at different levels remains one of the most challenging tasks, which has no unequivocal solution to date.

The main criterion for mental retardation is, according to the decision of the WHO Committee, is the IQ intelligence indicator. In order to determine the IQ various tests are being used (Veksler, Raven, Binet). At the same time, the use of these methods in the common practice is limited by the fact that the techniques themselves are voluminous, and the medical psychological-pedagogical commission is often in a strict time-frame.

Some variants of duration reproduction interruption in people with various defects of the psyche were the study subject of D. Elkin (19) and L. Belenkoy (24). Based on these studies, we had posed the hypothesis that the mentally retarded subjects throughout the chronometric testing process show apparent deviations in the accuracy of conducting the test. In order to test the hypothesis, the study was conducted on children with special needs in the form of oligophrenia, stage of debility, and children with delayed mental development.

Each child was given a duration, limited by two sounds of the chronoscope button. After the interval, the chronoscope was transmitted to the subject and he was given the task of reproducing the proposed interval using this apparatus. Having made sure that the child learned the way of using the chronoscope, we conducted several studies (at least 5 times). In the main series, the following intervals were used: $2,3,4,5 \mathrm{~s}$.

The number of signals was limited to 25 . By the results of the reproduction, the value of subjective time unit $(\tau)$ was calculated with the accuracy of time reproducing to $0.001 \mathrm{~s}$.

The mathematical analysis of the study results showed that oligophrenics and children with delayed mental development have a different deviation from the analogue of the "good" clock. In children with a delay in mental development there is a deviation from the accuracy of reproduction of given time intervals from 0.03 to 0.05 . In mentally retarded children it is from 0.05 to 0.1 (see Table 4). 
Table 4: Type of deviations from the analogue of "good" clock in children with mental development dysontogenesis

\begin{tabular}{|c|c|c|c|c|c|c|c|c|}
\hline \multicolumn{2}{|c|}{ Group } & $2 c$ & $3 c$ & $4 c$ & $5 c$ & $\sigma$ & IQ & $\mathbf{t}$ \\
\hline \multirow{2}{*}{1} & bots & 0.92 & 0.88 & 0.87 & 0.82 & $0.03-0.05$ & $70-85$ & \multirow{2}{*}{$0.001^{*}$} \\
\hline & girls. & 0.91 & 0.87 & 0.88 & 0.83 & $0.02-0.04$ & $70-85$ & \\
\hline \multirow[b]{2}{*}{2} & boys & 0.80 & 0.70 & 0.70 & 0.65 & $0.051-0.065$ & $60-69$ & \multirow{2}{*}{$0.01^{*}$} \\
\hline & girls. & 0.81 & 0.71 & 0.70 & 0.66 & $0.052-0.066$ & $60-69$ & \\
\hline \multirow{2}{*}{3} & boys & 1.30 & 0.88 & 0.86 & 0.70 & $0.066-0.075$ & $55-59$ & \multirow{2}{*}{$0.001^{*}$} \\
\hline & girls. & 1.31 & 0.87 & 0.87 & 0.71 & $0.066-0.075$ & $55-59$ & \\
\hline \multirow{2}{*}{4} & boys & 1.35 & 1.1 & 0.85 & 0.80 & $0.076-0.085$ & $52-54$ & \multirow{2}{*}{$0.01^{*}$} \\
\hline & girls. & 1.36 & 1.2 & 0.84 & 0.81 & $0.076-0.085$ & $52-54$ & \\
\hline \multirow{2}{*}{5} & boys & 1.96 & 1.50 & 1.30 & 0.85 & $0.086-0.1$ & $50-53$ & \multirow{2}{*}{$0.001^{*}$} \\
\hline & girls. & 1.95 & 1.51 & 1.31 & 0.84 & $0.086-0.1$ & $50-53$ & \\
\hline
\end{tabular}

NOTE: ${ }^{*} p<0.05$

At the same time, oligophrenics undergo several variants of deviation from the analogue of the "good" clock. The level of deviations resemblance was so similar that it is enough to use the results of "medium-group entities", which are given in Table 4.

Group 1 included children with delayed mental development. A characteristic feature is that they have a deviation from the norm of $\sigma$ in the range from 0.03 to 0.05 .

In group 2 there are mentally retarded children with deviations from the norm from 0,051 to 0,065 . It is this group that includes mentally retarded children with an IQ value of 60 to 69.

In group 3 there are mentally retarded children with a deviation from the norm from 0,066 to 0,075 . It is this group that includes mentally retarded children from the value of IQ from 55 to 59 .

Group 4 includes mentally retarded children with a deviation from the norm from 0.76 to 0.85 . It is this group that includes mentally retarded children from the value of IQ from 52 to 54 .

Group 5 includes mentally retarded children with a deviation from the norm from 0.86 to 1.0 . It is this group that includes mentally retarded children with an IQ of 50 to 52 .

$2,3,4,5$ groups show that variations in the hours of children that are mentally retarded somewhat more than in children with delayed mental development.

The kind of deviations from the analogue of "good" hours in mentally retarded children and children with delayed mental development is presented in Table 4.

In addition to the described groups with varying deviation degrees from the analogue of "good" clocks, another group of children who could not perform the experimental procedure, i.e. did not understand the task, was separated.

In accordance with the degree of deviation from the analogue of the "good" clock, children had a different level of intellectual development.

At the same time, there is a consistency between the level of the intellectual development and the ability to reproduce the proposed intervals by hearing.

Concurrently, children with a delay in mental development have a slight deviation from the norm in reproducing the proposed intervals of time.

\section{DISCUSSION}

On two independent samples, by the method of reproduction of duration (to $=2,3,5 \mathrm{~s}$ ), B. Tsukanov (16) received the value $E=15 \sim 16 \%$ for "medium-group subjects" (16). By magnitude, it completely coincides with the previously obtained values of relative error in the studies of G. Vudrou (20), T. Kolman (21), P. Fress (22), and others. If we take into account the fact that G. Vudrou (20) used intervals of up to $30 \mathrm{~s}$, T. Kolman (21) - up to 3 minutes, P. Fress (22) - up to $30 \mathrm{~s}$, and in B. Tsukanov (16) experimented with intervals of up to $5 \mathrm{~s}$, and to take into account that the practical equality of errors was separated by several decades, it can be said that by the method of duration reproduction the individual chronotype is determined, which is a constant value and can act as a central factor that determines the orientation of the individual, and precisely, extraversion-ambivertness-introversion and predicts the flow of mental development dysontogenesis. The unit of measure of time is the subjective "step" ( $\tau)$, which in different individuals has its own duration. Within the four typological groups, this "step" at different periods of subjective time allows us to introduce the concept of individual clock quality. Based on quality, we can talk about "good" and "bad" clocks (23). 
Comparing the quadratic deviations of $\sigma$ (individual clock quality index) in subjects of representative sample with the level of their psychometric intelligence (IQ), B. Tsukanov (16) got a simple dependence: the smaller $\sigma$, the higher the IQ of a person (16).

The quality of an individual's watch, like the clock itself, is innate, so the quality score $(\sigma)$ should be considered as one of the indicators of the basic intellectual potential ("factor g") of the individual.

The concept of chronopsychological prognosing proposed by Savenkova I.I. required the development of a method that can be used to study the mental development dysontogenesis of preschool children (18).

To determine the chronotype, the relation $\mathrm{Xt}=\mathrm{ts} / \mathrm{t} 0$ proposed by $\mathrm{G}$. Ehrenwald (17) was used. Calculations conducted on the results of the reproduction of the duration of "medium-subjects" showed that in both "subjects" Xt $=$ const at different intervals of the experienced time. According to the value of $\mathrm{Xt}$, the range of relative errors varies from $10 \%$ to $30 \%$. Individuals of both samples were divided into two groups (16).

The first group includes individuals with ts/t0 that can't measure a particular time period fully. The range of their errors is from 0 to $30 \%$. In the second group there are individuals with ts $>t 0$, which over-measure the given time period, the range of errors which is from 1 to $10 \%$. As you can see, we can talk about "hurrying", "exact" and "slow" individuals. Every individual that under-measures or over-measures time is called a "chronotype".

The sample was tested for the stability of the individual "chronotype". Determining the "chronotype" for each subject for several months, it was found that the deviation of the mean values does not exceed the resolution of the 1st-class chronoscope (16). The obtained data give reason to believe that the chronotype of the individual is characterized by high stability, and therefore can act as a central factor that can combine the psychotype and somatotype of the individual, and accordingly predict the course of the mental development dysonotogenesis

Thus, the results of the duration reproduction relative error in the experimental group obtained in the research results are equivalent to the results of the duration reproduction relative error in the control group and are subject to unambiguous interpretation, which confirms the results of the research in the works of B.Y. Tsukanov (16) and I.I. Savenkova (18). The proposed thesis of B. Tsukanov (16) about the connection of the accuracy of subjective "clock" of an individual with a level of giftedness and the level of intelligence acquires a new meaning. According to the proposed model, the accuracy of the individual "clock" of the individual should be understood as the accuracy and quality of the information display of the cognitive system, which becomes a guarantee of the disclosure of intellectual development of the child. Thus, the duration reproduction method can be considered adequate to prognose the mental development dysontogenesis course from the standpoint of the laws of experiencing time.

In this regard, the specificity of the reproduction method can reveal the peculiarities of the "time mechanism" of the individual, which measures the length of time experienced by the subject through his chronotype.

\section{CONCLUSION}

Thus, the research results allow us to conclude that subjective time unit performs the function of "step", which measures the flow of time experienced by the subject. As a stable unit, the chronotype provides the integrity and structure of the experience of time.

In the case of a delay in mental development, the unit itself is stable, does not change in the reproduction of different time intervals.

In patients with mental retardation it changes in a jumping manner depending on the depth of the mental defect. In other words, due to the jump in the psyche of an oligophrenic patient there is no proper structure of the direct experience of time. Therefore, it becomes possible to assume that in such groups of children there are difficulties in the assimilation of time concepts, the difficulty in shaping the imagination about the metric properties of time, and the disorder of orientation in the past and the future in oligophrenic patients is determined by the deviation from the analogue of "good" clocks.

A comparison of mean values by the Student's t-test convinces that gender differences between the ability to reproduce specified intervals in girls and boys (mentally retarded children and children with delayed mental development) do not exist.

The results of the conducted research allow to further build a model "chronopsychological portrait" of the child with a delay of mental development and a model "chronopsychological portrait" of the mentally retarded child. 


\section{REFERENCES}

1. Synov VM. Correctional psychopedagogy. Oligophrenic pedagogy. Kyiv: NPU imeni M.P. Drahomanova; 2009.

2. Desai G, Chaturvedi SK. Daiyt li diagnosticheskie kriterii psihosomaticheskih issledovanii diagnosticu somaticheskih simptomov s medecinskoi tochki zrenia. Psychother Psychosom. 2016;85:121-122. https://doi.org/10.1159/00041063 PMid:26807856

3. Fizeshi O. Historical-System Model of the Development of Primary School in Transcarpathia at the Tum of XIXXX Centuries. Science and education. 2017;12:15-23.

4. Slepovich ES. Forming speech in preschool children with a delay in mental development. Minks: Nar. Asveta; 1989.

5. Sokolova EV. Psychology of children with delayed mental development. Moscow: TC Sfera; 2009.

6. Wendt J, Hamm A, Pane-Farre C. Pretreatment Cardiac Vagal Tone Predicts Dropout from and Residual Symptoms after Exposure Therapy in Patients with Panic Disorder and Agoraphobia. Psychotherapy and Psychosomatics. 2018;87:187-9. https://doi.org/10.1159/000487599

7. Viskovatova TP. Game method in correction of cognition in children with STP in conditions of sanatorium and spa treatment. ONU Journal. 2010;10:32-147.

8. Elkelboom EM, Tak LM, Roest AM, Rosmalen JG. A systematic review and meta - analysis of the percentage of revised diagnoses in functional somatic symptoms. Journal of Psychosomatic Research; 2016;88:60-7. https://doi.org/10.1116/50022-3999(16)30364-6

9. Parsons T. The Social System. New York: The Free Press; 2015.

10. Savenkova II. Chronopsychological prognosing of disorder experience in psychosomatic patients. Kyiv: KU imeni B.Hrinchenka; 2013.

11. Flammer A. Developmental analysis of control beliefs. New York: Cambridge University Press; 2015.

12. Hargreaves DH. Personalizing learning: Next steps in working laterally. London: Specialist school Trust; 2014.

13. Fova GA, Cosci F, Sonino N. Current psychosomatic practice. Psychother Psychosom. 2017;86:13-30. https://doi.org/10.1159/000448856

14. Henningsen P, Zipfel S, Sattel H, Creed F. Management of Functional Somatic Syndromes and Bodily Distress.

15. Psychotherapy and Psychosomatics. 2018;87(1):12-31. https://doi.org/10.1159/000484413 PMid:29306954

16. Vlasova TA. About the children with mental retardation. St. Petersburg: Piter; 2015.

17. Tsukanov BY. Time in human psyche. Odesa: Astroprint; 2000.

18. Ehrenwald H. Versuche zur Zeitauffassung des Unbewussten Arche. New York: Psychologie; 2014.

19. Savenkova II. Chronopsychological prognosing of psychosomatic disorders experience. Science Rise. 2015;2:8790.

20. Elkin DG. Experiencing time. Doctors thesis. Odessa: ONU imeni I.I. Mecnikova; 1945.

21. Vudrou G. Percieving time. Moscow: Inostrannaia literature; 1963.

22. Kolman T. The effect of handness on the perception of simultaneity and temporal order. New York: Psychologie; 2015.

23. Fress P. Human to time adaptation. Moscow: Progress; 1961.

24. Kuralova AV. Peculiarities of time perspective influence on basic parts of self-effectiveness. Science and education. 2017;11:92-7.

25. Belenkoy L. Ob uslovnyh refleksah na vremia u muzykantov. Odessa: Astroprint; 2013.

$\diamond \diamond \diamond \diamond \diamond \diamond \diamond$

http://www.ejgm.co.uk 